\title{
Food allergy: nuts and tree nuts
}

\author{
Jesus F. Crespo ${ }^{1 *}$, John M. James ${ }^{2}$, Consuelo Fernandez-Rodriguez ${ }^{1}$ and Julia Rodriguez ${ }^{1}$ \\ ${ }^{1}$ Hospital Universitario Doce de Octubre, Madrid, Spain \\ ${ }^{2}$ Colorado Allergy and Asthma Centers, Fort Collins, CO, USA
}

\begin{abstract}
Nuts are a well-defined cause of food allergy, which affect approximately $1 \%$ of the general population in the UK and the USA. There do appear to be differences in the frequency of nut allergy between different countries because of different dietary habits and cooking procedures. For example, in the USA and France, peanuts are one of the most frequent causes of food allergy, but in other countries, it seems to be less common. Genetic factors, in particular, appear to play a role in the development of peanut allergy. While the majority of nut allergens are seed storage proteins, other nut allergens are profilins and pathogenesis-related protein homologues, considered as panallergens because of their widespread distribution in plants. The presence of specific IgE antibodies to several nuts is a common clinical finding, but the clinical relevance of this cross-reactivity is usually limited. Allergic reactions to nuts appear to be particularly severe, sometimes even life-threatening, and fatal reactions following their ingestion have been documented. Food allergy is diagnosed by identifying an underlying immunological mechanism (i.e. allergic testing), and establishing a causal relationship between food ingestion and symptoms (i.e. oral challenges). In natural history investigations carried out in peanut-allergic children, approximately $20 \%$ of the cases outgrew their allergy or developed oral tolerance. The treatment of nut allergies should include patient and family education about avoiding all presentations of the food and the potential for a severe reaction caused by accidental ingestion. Patients and families should be instructed how to recognise early symptoms of an allergic reaction and how to treat severe anaphylaxis promptly.
\end{abstract}

Peanut allergy: Nut allergy: Tree nut allergy: Allergens: Food allergy

Nut and tree nut consumption has been proven to be a healthy dietary habit. For example, several studies show that nuts have a beneficial effect on the outcome of coronary disease and cholesterol serum levels. However, nuts and tree nuts are among the highest producers of IgE-mediated allergic reactions following food ingestion (Table 1). Food allergy is estimated to affect approximately $6-8 \%$ of children below 4 years of age and $1-2 \%$ of individuals over the first decade of life. In the United States, food allergy produces approximately 30000 anaphylactic reactions and 200 fatalities per year (Sampson, 2002). Especially in the United States, peanut allergy has emerged as an important health problem, with considerable consequences for patients, families, schools, health care professionals and the food industry. Moreover, it has recently been demonstrated that peanut allergy has a significant impact on quality of life and family relationships, similar to some rheumatologic diseases (Primeau et al. 2000). Allergic reactions to nuts other than peanuts seem to be less frequent although their role as a cause of severe or fatal reactions has been well documented.

In the last few years there has been an increase in nut and tree nut consumption because of their favourable health effects. The production of processed foods containing nuts as components has also increased. This could facilitate contamination of other food products being handled in the same food manufacturing line (Teuber et al. 2003). These facts could be important causes of the apparent increase in prevalence of peanut allergy. They could also be related to the frequency of reactions produced by inadvertent ingestion in more than $50 \%$ of patients allergic to peanuts and in $15-$ $30 \%$ of patients allergic to other nuts in the years following diagnosis and dietary avoidance of nuts.

\section{Epidemiology}

Nuts are the foods that most frequently cause fatal anaphylactic reactions. A recent analysis of thirty-two fatal food allergic reactions in the United States from 1994-1999 showed peanuts and other nuts to be responsible for 63 and $31 \%$ of the deaths, respectively. All fatalities in patients over 6 years of age were caused by this food group (Bock et al. 2001). Surveys carried out in the UK and the United States showed an estimated prevalence of allergic reactions to nuts of approximately $1 \%$ in the general population. A cohort of 1218 newborns followed up to 4 years of age in the Isle of Wight yielded a percentage of $0.7 \%$ with clinically-important reactions to nuts (six to peanuts, one to hazelnuts and one to cashews) (Tariq et al. 1996). A random-digit telephone survey of 4374 households in the United States provided information about 12032 individuals, and the prevalence of food allergy to nuts was estimated to be $1.1 \%$ (Sicherer et al. 1999). Both of these investigations were based on reactions reported by participants without any further diagnostic procedures; therefore the actual prevalence could have been overestimated. 
Table 1. Nuts and tree nuts implicated in IgE-mediated reactions

\begin{tabular}{|c|c|c|}
\hline Family & Species & Common name \\
\hline Leguminoseae & Arachis hypogea & Peanut \\
\hline Betulaceae & Corylus avellana & Hazelnut \\
\hline \multirow[t]{2}{*}{ Anacardiaceae } & Anacardium occidentale & Cashew \\
\hline & Pistacia vera & Pistachio \\
\hline \multirow[t]{2}{*}{ Juglandaceae } & Juglans regia & Walnut \\
\hline & Carya illinoinensis & Pecan nut* \\
\hline Rosaceae & Prunus dulcis & Almond* \\
\hline Lecythidaceae & Bertholletia excelsa & Brazil nut \\
\hline Fagaceae & Castanea sativa & Chestnut* $^{*}$ \\
\hline Pinaceae & Pinus pinea & Pine nut* \\
\hline Proteaceae & Macadamia intergrifolia & Macadamia nut* \\
\hline Palmaceae & Cocos nucifera & Coconut $^{*}$ \\
\hline
\end{tabular}

*Infrequent or anecdotally described as causing allergic reactions.

In a more recent study carried out in the Isle of Wight in children of 3-4 years of age, clinical allergy to peanuts was established by oral challenges to be $1.5 \%$ (Grundy et al. 2002). With this in mind, it has been suggested that the incidence of peanut allergy could have increased in the last few years. In a study carried out in a population from the UK, a significant increase in the prevalence of peanut allergy assessed by skin testing was found, ranging from $1.1 \%$ in 1989 to $3.3 \%$ in 1994-1996. The reported prevalence of clinical allergy to peanut increased from 0.5 to $1 \%$ in this period of time, although the differences were not significant (Grundy et al. 2002). The increase in peanut sensitisation may be related to earlier exposure to the allergen, the availability of more food products containing small amounts of peanuts and their presence in foods frequently consumed in childhood, such as peanut butter.

In general, the prevalence of adverse reactions to foods is higher in children than in adults. Surveys carried out in the general population, however, show that allergy to nuts is an important problem in adulthood. In the UK, the perceived prevalence of peanut allergy ranges between $0.61 \%$ in children below 14 years of age, $0.53 \%$ in individuals from 15 to 44 years and $0.3 \%$ in adults over 44 years, with a significant predominance in women in the group of adult subjects (Emmett et al. 1999). In a study carried out in the USA, the perceived prevalence of allergy to nuts obtained by a telephone survey was higher in adults $(1.6 \%)$ than in children (0.6\%) (Sicherer et al. 1999). As allergy to nuts persists over the years, these data could reflect a cumulative effect in adults. This fact is supported by a study carried out on 142 patients below 30 years of age diagnosed with peanut allergy. Forty-six percent reported their first reaction to peanuts in the first year of life and $80 \%$ below three years of age (Moneret-Vautrin et al. 1998).

Although nuts have been described as one of the main food groups to cause allergic reactions, there are considerable differences in occurrence between different geographic areas. While in the United States and France peanuts are one of the most frequent causes of food allergy, this does not seem to be the case in Spain and other countries (Crespo et al. 1995). Similarly, the relative frequency of different nuts as a cause of food allergy changes in different areas. Although this might be due to nonhomogeneous study designs, it may also reveal the importance of different dietary habits in the development of specific food allergy. Differences in cooking methods commonly related to cultural factors may also contribute to the increase in prevalence of nut allergy observed in different countries. For example, peanut allergy is not common in China although its consumption per capita is similar to that in the United States. Most of the peanuts consumed in the latter country are dry roasted, including those used to process peanut butter, while in China peanuts are generally boiled or fried before consumption. The higher temperatures produced in the dry-roasting process $\left(150^{\circ} \mathrm{C}\right)$ compared to boiling $\left(100^{\circ} \mathrm{C}\right)$ or frying $\left(120^{\circ} \mathrm{C}\right)$ increase the allergenic potency of three major allergens of peanuts (Beyer et al. 2001). Moreover, the difference in frequency of peanut allergy in China and the United States does not appear to be due to genetic factors, as the prevalence in the Chinese population living in the United States is similar to that observed in the American population.

In contrast, it has been established that genetic factors may exert an influence on the development of peanut allergy. In studies carried out in the UK, the frequency of this condition has been found to be significantly higher in relatives of peanut allergy patients than in the general population ( $7 \% v .0 .5 \%)$. There is also a possible association with HLA class II genes (Howell et al. 1998). In a study carried out in fifty-eight pairs of twins, $7 \%$ of dizygotes shared peanut allergy $v$. $64 \%$ monozygotes, which suggests a significant genetic influence. The probability of inheriting peanut allergy was estimated to be $81.6 \%$, a percentage similar to other allergic diseases, such as asthma (87\%), atopic dermatitis (74\%) and allergic rhinitis (74-82\%) (Sicherer et al. 2000).

\section{Immunopathology}

IgE-mediated reactions are the most extensively studied and best defined group of all food adverse reactions. A failure in development, or a breakdown of oral tolerance, leads to an increased production of specific IgE antibodies, which bind to high-affinity IgE receptors $(\mathrm{Fc} \in \mathrm{I})$ on the surface of mast cells, basophils, Langerhans cells and monocytes of atopic subjects. They also bind to low-affinity receptors for IgE (FceII) on antigen-presenting cells (macrophages, monocytes, Langerhans cells and dendritic cells), lymphocytes, eosinophils and platelets. When food allergens cross mucosal barriers and cross-link to IgE antibodies already bound to their high-affinity receptor on mast cells and basophils, mediators such as histamine, prostaglandins and leukotrienes are released. These mediators induce vasodilation, smooth muscle contraction and mucus secretion. These events constitute the clinical manifestations of allergic response. Activated mast cells also release several cytokines (IL-4, IL-5, TNF- $\alpha$, platelet activating factor), all of which facilitate inflammation. (Kay, 2001).

\section{Sensitisation to nuts}

One main feature of IgE-mediated allergic reactions is that an initial sensitising contact with the allergen must occur. Thid contact promotes the synthesis of specific IgE antibodies that bind to their high-affinity receptors on target cells, so that in successive exposures an allergic reaction can take place. However, up to $70 \%$ of adverse allergic reactions to 
peanuts and other nuts occur after the first exposure. Therefore, it has been pointed out that possible inadvertent, previous ingestion of minimal quantities, or prior cutaneous exposures to substances that contain peanuts or peanut oil might play a role (Sicherer et al. 1998). In addition, the possibility of intra-uterine sensitisation or the presence of peanut proteins in breast milk has been suggested. In contrast, a recent study has documented the low allergenicity of vitamin pills containing refined peanut oil (Kull et al. 1999). The strict avoidance of the most allergenic foods, such as nuts, in the last trimester of pregnancy and throughout lactation reduces the frequency of onset of atopic dermatitis and food allergy. Nevertheless, this effect is limited to the first two or three years of life (Zeiger, 2003). Although the individual effect of intrauterine or early-in-life exposure to a particular food has not been elucidated, high maternal consumption of peanuts in pregnancy, and early introduction during infancy, have been correlated with a higher frequency of sensitisation.

Peanut allergy can be transferred with a liver transplantation from an allergic donor (Legendre et al. 1997; Phan et al. 2003). Food allergy, particularly peanut, has also been documented in organ recipients receiving immunosuppressive treatment with Tacrolimus. Several mechanisms by which Tacrolimus could facilitate the development of allergy have been proposed: for example, the increase in intestinal mucosal permeability or the inhibitory effect of interleukine 2 (IL-2), which could favour type $\mathrm{T}_{\mathrm{H}} 2$ immune responses. In spite of the widespread use of this drug in adult patients, however, all cases described so far have taken place in children, which suggests that the effect of Tacrolimus could be more significant in an immature immune gastrointestinal system (Nowak-Wegrzyn et al. 2001).

\section{Allergens}

So far, only a limited number of allergens in cashews, hazelnuts, peanuts, chestnuts, walnuts and Brazil nuts have been identified (Table 2) (Burks et al. 2001; Roux et al. 2003). The most important source of information has been the study of recombinant proteins from complementary DNA libraries of cashews, hazelnuts, peanuts and walnuts. The characterisation of these allergens, and others obtained by means of protein purification, has made it possible to document that the majority of nut allergens are seed storage proteins, such as vicilins (7S globulins composed of subunits of about $50 \mathrm{kD} \mathrm{MW})$, legumins (11-13S globulins with subunits composed of acidic peptides of 30-40 kD MW and basic peptides of $15-20 \mathrm{kD} \mathrm{MW}$ ) and $2 \mathrm{~S}$ albumins (15 kD MW). The cloning and sequencing of recombinant proteins from walnuts (Juglans regia) shows that the Jug $\mathrm{r} 2$ allergen belongs to the vicilin family, with a $75 \%$ homology to the Ara $\mathrm{h} 1$ allergen from peanuts (Arachis hipogea). The allergen Ana o 1 from cashews (Anacardium occidentale) has been identified as a vicilin protein, although the analysis and epitope comparison does not show a significant homology with those from peanuts Ara h 1. A seed storage protein from hazelnuts (Corylus avellana), designated as Cor a 11, has been shown to be a vicilin. An $11 \mathrm{~S}$ globulin of the legumin type (Cor a 9) from hazelnuts has been documented as homologous to allergens Ana o 2 from cashews, Ara h 3 from peanuts and soybeans glycinin. Sera from patients allergic to Brazil nuts (Bertholletia excelsa)
Table 2. Nut allergens

\begin{tabular}{|c|c|c|c|}
\hline & Allergen & Function/Type & M.W. (kD) \\
\hline \multirow[t]{2}{*}{ Cashew } & Ana o 1 & Vicilin (7S) & 59 \\
\hline & Ana o 2 & Legumin (11S) & \\
\hline \multirow[t]{5}{*}{ Hazelnut } & Cor a 1 & PR-10 (Bet v 1 homologous) & 17 \\
\hline & Cor a 2 & Profilin & 14 \\
\hline & Cor a 8 & PR-14 (LPT) & 9 \\
\hline & Cor a 9 & Globulin (11S) & 40 \\
\hline & Cor a 11 & Vicilin (7S) & 48 \\
\hline \multirow[t]{8}{*}{ Peanut } & Ara h 1 & Vicilin & 63.5 \\
\hline & Ara h 2 & Conglutin & 17 \\
\hline & Ara h 3 & Glicinin & 60 \\
\hline & Ara h 4 & Glicinin & 37 \\
\hline & Ara h 5 & Profilin & 15 \\
\hline & Ara h 6 & Conglutin homologous & 15 \\
\hline & Ara h 7 & Conglutin homologous & 17 \\
\hline & Ara h 8 & PR-10 & 17 \\
\hline \multirow[t]{2}{*}{ Chestnut } & Cas s 5 & Chitinase $\mathrm{lb}$ & \\
\hline & Cas s 8 & PR-14 (LPT) & $9 \cdot 7$ \\
\hline \multirow[t]{2}{*}{ Brazil nut } & Ber e 1 & Albumin (2S) & 9 \\
\hline & Ber e 2 & Legumin (11S) & 29 \\
\hline \multirow{4}{*}{ Walnut } & Jug $r 1$ & Albumin (2S) & 14 \\
\hline & Jug $r 2$ & Vicilin (7S) & 44 \\
\hline & Jug r 3 & PR-14 (LTP) & 9 \\
\hline & Jug $r 4$ & Legumin (11S) & \\
\hline
\end{tabular}

LTP: lipid transfer proteins.

reacted with proteins $21-22 \mathrm{kD}$ and $33 \cdot 5 \mathrm{kD} \mathrm{MW}$, identified as subunits $\alpha$ and $\beta$ from a legumin- type $12 \mathrm{~S}$ globulin. $2 \mathrm{~S}$ albumins are abundant in Brazil nuts; its major allergen Ber e 1 has a high methionine content (18\%), so $2 \mathrm{~S}$ Brazil nut albumins were considered as good candidates to augment methionine content in methionine-deficient crops by means of ADN technology. Ber e 1 genetically-modified soybeans are considered the paradigm of an experimental transfer of an allergen by means of recombinant technology. An allergen from walnut Jug $\mathrm{r} 1$ has been identified as a $2 \mathrm{~S}$ prealbumin (15$16 \mathrm{kD} \mathrm{MW}$ ). This protein is highly homologous in its sequence to allergens from Brazil nuts (Ber e 1), castor beans, and cotton and mustard seeds.

Other allergens from nuts, such as profilins and pathogenesis-related protein (PR) homologues, which have a known biological function, are considered to be panallergens because of their contribution to the allergenicity of an ample group of pollens, nuts, seeds, fresh fruit and other vegetables (Breiteneder \& Ebner, 2000). Profilins were first identified as allergens in birch pollen (Bet $\mathrm{v} 2$ ). They are now recognised as ubiquitous allergens, responsible for extensive immunological cross-reactivity between airborne allergens and foods. Hazelnut profilin (Cor a 2) has been documented as an important allergen in a small group of patients allergic to hazelnut pollen and hazelnuts. Peanut profilin (Ara h 5) has also been characterised and expressed as a recombinant allergen. Many vegetable allergens that have been identified are homologues of PR proteins, whose expression is induced by pathogens, wounds or certain types of environmental stress (Midoro-Horiuti et al. 2001). PR-3 type proteins are classified as basic class I chitinases; they have an N-terminal domain, known as hevein, which is present in allergens Hev b 6 from natural rubber latex, Cas s 5 from chestnut, Pers a 1 from avocados and bananas. All of this explains the cross-reactivity between these fruits and latex. Bet v 1, which is a major allergen from 
birch pollen, belongs to the type 10 PR family; its homologues have been identified in a large group of pollens (particularly Phagales) and foods. Cor a 1 from hazelnuts has a high homology $(85 \%)$ with Bet $\mathrm{v} 1$ from birch pollen and to a lesser extent with hazelnut pollen. This similarity seems to be responsible for the clinical association between pollen and hazelnut allergy, which is very common in central and northern Europe, with oral allergy syndrome as the typical clinical presentation. Lipid transfer proteins (LTP) are a group of $9 \mathrm{kD}$ polypeptides, which are widespread in the plant kingdom. They have been identified as homologues to PR 14-type proteins. LTPs are the leading allergens in Rosaceae fruits, such as peaches, apples and apricots, especially in fruit-allergic patients without associated pollen allergy. In the nut group, PR-14 homologues have already been identified in hazelnuts (Cor a 8), walnuts (Jug r 3 ) and chestnuts (Cas s 8). This allergen has $53 \%$ identity with LTP from apples (Mal d 3) and $50 \%$ with peaches (Pru p 3) and Artemisia pollen LTPs. Cross-reactivity between LTPs from peaches, apples, Artemisia pollen and chestnuts has been documented in studies carried out by skin testing. It has been suggested that patients allergic to chestnut LTP could be primarily sensitised to Artemisia pollen.

\section{Cross-reactivity between different nuts}

The presence of serum specific IgE antibodies to several nut species (sensitisation or immunological reactivity) is a common finding. Of 142 patients allergic to peanuts, $50 \%$ had positive skin tests to almonds, $40 \%$ to cashews, $30 \%$ to pistachios, $26 \%$ to Brazil nuts and $21 \%$ to hazelnuts (Moneret-Vautrin et al. 1998). The possible homology between allergens such as $2 \mathrm{~S}$ albumins, vicilins, legumins, profilins and LTPs could theoretically explain this wide immunological cross-reactivity. However, it must be taken into account that a single amino acid substitution in an allergen can modify its IgE antibody binding capacity or the affinity of the bond. Therefore, some highly homologous proteins do not exhibit immunological cross-reactivity and, even when they do, the clinical significance of the finding can be limited. While $63 \%$ of nineteen patients who were clinically allergic to peanuts showed positive skin testing to other nuts, oral challenges carried out with these nuts yielded a negative result (Bock \& Atkins, 1989). In series with a higher number of similar patients, between 28 and $49.5 \%$ were found to be clinically reactive to several nuts (Ewan, 1996; Hourihane et al. 1996; Sicherer et al. 1998; Sicherer et al. 2001).

\section{Clinical symptoms}

The clinical features of allergic reactions to foods are acute in onset, with symptoms occurring within minutes or a few hours after ingestion. Although systemic anaphylactic reactions to foods are clinically similar to those produced by other agents (e.g. insect stings, medications, etc.), in the former, oral and pharyngeal pruritus, cutaneous erythema, urticaria and angioedema, chest tightness, nausea, vomiting and colicky abdominal pain may appear as early symptoms. In severe reactions, progressive respiratory symptoms, hypotension and dysrhythmias may take place. Laryngeal obstructive oedema is infrequent and cutaneous symptoms may be absent in severe cases. A detailed analysis of severe and fatal reactions shows that a delay in epinephrine administration is associated with a poorer prognosis. Up to one-third of severe reactions may have a biphasic course, during which there is an initial improvement in symptoms followed by a sudden worsening of severe bronchospasm, which can be refractory to treatment and frequently requires mechanical ventilation. The mechanism of biphasic reactions is unknown, but it seems to be more frequent when therapy is delayed or the symptoms at onset are more severe. Therefore, allergic reactions to food comprise a wide spectrum of acute symptoms and signs that can range from isolated oral symptoms, acute urticaria and/ or angioedema, or gastrointestinal anaphylaxis to multiple organ manifestations typical of anaphylactic shock (Sampson, 2002).

In comparison with other foods, allergic reactions to nuts seem to be particularly severe, with multisystemic or respiratory symptoms in up to $81 \%$ of the cases. The role of nuts as a cause of fatal and life-threatening reactions is well documented. In a questionnaire survey carried out on 5159 patients allergic to nuts, acute cutaneous and respiratory symptoms were the most frequent clinical features. Approximately $50 \%$ of the reactions affected several organs and asthmatic patients experienced severe reactions more frequently. Younger patients usually had their first reactions at home (approximately $70 \%$ ), while successive reactions generally occurred in school, restaurants or in the houses of friends or relatives (Sicherer et al. 2001).

The clinical features of allergic reactions to peanuts, hazelnuts and cashews have been described on large series of patients. Reactions to peanuts can be provoked by exposure to minimal amounts of the food, or even by skin contact or inhalation. Quantities below $100 \mathrm{mg}$ can produce subjective symptoms, although doses typically causing reactions range between $100-1000 \mathrm{mg}$. In a review of 102 allergic reactions to peanuts in children, onset of symptoms took place in all cases in the first $45 \mathrm{~min}$ after ingestion. In $95 \%$ of reactions, symptoms appeared in the first $20 \mathrm{~min}$ (Sicherer et al. 1998). The most frequent clinical manifestations were acute urticaria/angioedema (49\%), followed by systemic anaphylaxis (acute urticaria, dyspnoea, pharyngeal tightness, irritative cough, vomiting and/or diarrhoea) $(21 \%)$. Isolated gastrointestinal (vomiting, acute diarrhoea) or respiratory symptoms appeared infrequently (2\%). Around half of the patients with rhinoconjunctivitis and/or asthma due to allergy to the Phagales family of pollens, particularly birch, have detectable serum specific IgE to hazelnut allergens. These patients usually present with oropharyngeal symptoms (i.e. oral allergy syndrome). Cross-reactivity between allergenic proteins from tree pollens homologous to allergen Bet $\mathrm{v} 1$ from birch (PR10) and allergen Cor a 1 from hazelnuts may be responsible for the symptoms. Severe allergic reactions to hazelnuts including urticaria, angioedema, bronchospasm, vomiting, laryngeal oedema, diarrhoea and/or systemic anaphylaxis have also been described in patients who are not allergic to pollen. In these cases, other allergenic proteins such as Cor a 8 (LTP) and Cor a 9 (11S globulin) seem to be relevant (Pastorello et al. 2002). Allergic reactions to cashews usually occur (88-96\% of cases) on being exposed to the food for the first time. Although its onset in adult life has been described, the first reactions usually happen in childhood, frequently with 
minimal amounts of the food. In a recent study carried out on forty-two children with cashew allergy, the mean age at onset was 2 years. One-third of the patients were also allergic to pistachios, which belongs to the same botanical family. The most frequent clinical symptoms were cutaneous $(76 \%)$, followed by respiratory $(25 \%)$ and gastrointestinal (17\%) (Rance et al. 2003). Allergic reactions to other nuts such as walnuts, almonds, Brazil nuts, pistachios, macadamia nuts, pine nuts, pecan nuts and coconuts are less common and have been reported anecdotically. Chestnut allergy is generally observed in the context of latex-fruit syndrome (Teuber et al. 2003).

\section{Diagnosis}

Allergic reactions to foods are diagnosed by identifying the underlying immunological mechanism (i.e. allergy testing) and establishing a reliable cause-effect relationship between ingestion of the suspected food and the clinical manifestations reported by the patient (i.e. oral challenges). The diagnostic approach begins with a clinical history and a physical examination. The comprehensive patient interview should include specific questions on the presence of acute symptoms and signs related to the suspected food ingestion. The clinical history explores the probability of food allergy with questions on the type of symptoms, the temporal relationship between ingestion and symptoms and the suspected food. Other simultaneously ingested foods should also be considered, as well as the possible contamination or the presence of other components in the ingested food. Generally, fewer than $40 \%$ of the reactions reported in the clinical history are then confirmed with double-blind, placebo-controlled food challenges.

\section{Allergy testing}

The purpose of allergy testing is to demonstrate an underlying IgE-mediated immunological mechanism, by means of skin testing or in vitro immunological techniques for detecting serum $\mathrm{IgE}$ antibodies. Skin tests are very useful in the initial evaluation of patients who report adverse reactions to foods. They are carried out by puncturing (i.e. prick or percutaneous) the skin with commercial glycerinated food extracts or by the prick-prick technique with fresh foods. A positive result for skin tests only suggests the possibility of an association between the suspected food and clinical reactivity, as the positive predictive value of skin testing with foods is $60 \%$ that of the outcome of oral challenges. However, negative skin test results can be used to exclude a possible IgE-mediated allergic reaction to a food.

Since the discovery of $\mathrm{IgE}$ in the late 1960s, several isotopic and enzymatic immunoanalyses have been developed to detect specific IgE antibodies. The values are positively correlated with the probability of clinical reactivity but not with the severity of the reaction. For example, with this method, values equal to or over $15 \mathrm{kU} / \mathrm{L}$ for specific $\operatorname{IgE}$ to peanut have a $100 \%$ positive predictive value of a positive oral challenge with peanut (Sampson, 2001).

The diagnostic accuracy of skin testing and specific serum $\mathrm{IgE}$ antibodies in relation to the outcome of oral challenges has only been assessed for two nut species: peanuts (Table 3) and hazelnuts (Table 4) (Ortolani et al. 2000; Sampson, 2001). However, these results should only be generalised with caution, as they may vary with the characteristics of the different
Table 3. Performance characteristics of skin testing and specific IgE in the diagnosis of clinical allergy to peanut

\begin{tabular}{|c|c|c|c|c|}
\hline & $\begin{array}{c}\text { Sensitivity } \\
(\%)\end{array}$ & $\begin{array}{l}\text { Specificity } \\
(\%)\end{array}$ & $\begin{array}{l}\text { PPV } \\
(\%)\end{array}$ & $\begin{array}{l}\text { NPV } \\
(\%)\end{array}$ \\
\hline Skin testing (prick) & $71-100$ & $29-62$ & $28-55$ & $75-100$ \\
\hline $\begin{array}{l}\text { ImmunoCAP FEIA } \\
\text { (positive result } \\
\geq 0 \cdot, 35 \mathrm{kU} / \mathrm{L} \text { ) }\end{array}$ & 97 & 38 & 78 & 85 \\
\hline $\begin{array}{l}\text { ImmunoCAP FEIA } \\
\quad(\text { result } \geq 15 \mathrm{kU} / \mathrm{L})\end{array}$ & 57 & 100 & 100 & 36 \\
\hline
\end{tabular}

$\mathrm{PPV}=$ positive predictive value, NPV = negative predictive value.

populations studied (age, clinical history, presence of atopic dermatitis) and prevalence of the disease in a particular population.

\section{Oral food challenges}

Oral challenges are the gold standard for diagnosing clinical allergy to food (Bruijnzeel-Koomen et al. 1995). Skin testing and specific serum $\operatorname{IgE}$ antibody determinations detect immunological reactivity, identifying the pathogenic mechanism of the reaction, but giving no evidence of clinical reactivity. Food ingestion occurs several times a day, which facilitates a temporal association between meals and the onset of clinical symptoms, especially when they are unspecific and repetitive. An oral food challenge is the only definite method for establishing a causal relationship between the ingestion of a particular food and the clinical symptoms reported. The only case in which it would not be used would be a convincing history of severe anaphylaxis after the ingestion of an isolated food. Oral food challenges may be performed in an open, single-blind, placebo-controlled or double-blind, placebo-controlled fashion, which is the most rigorous and objective method. During the double-blind, placebo-controlled food challenge (DBPCFC), the patient is given increasing doses of food or placebo, masked in a vehicle, with dose intervals of between $15-30 \mathrm{~min}$. If symptoms appear, the procedure is stopped and the appropriate treatment is administered. If the patient is given all the doses with no evidence of an adverse reaction, the result of the challenge is considered negative and a final open challenge is carried out with a usual serving of the food. These challenges should always be performed in an appropriate setting, with medical personnel trained in the management of

Table 4. Performance characteristics of skin testing and specific lgE in the diagnosis of clinical allergy to hazelnut.

\begin{tabular}{lcccr}
\hline & $\begin{array}{c}\text { Sensitivity } \\
(\%)\end{array}$ & $\begin{array}{c}\text { Specificity } \\
(\%)\end{array}$ & $\begin{array}{c}\text { PPV } \\
(\%)\end{array}$ & $\begin{array}{c}\text { NPV } \\
(\%)\end{array}$ \\
\hline $\begin{array}{c}\text { Skin testing (prick) } \\
\text { with commercial extract }\end{array}$ & 89.5 & 5.5 & 92.6 & 3.9 \\
$\begin{array}{c}\text { Skin testing (prick-prick) } \\
\text { with fresh food } \\
\begin{array}{l}\text { ImmunoCAP FEIA } \\
\text { (positive result } \\
\geq 0.7 \mathrm{kU} / \mathrm{L})\end{array}\end{array}$ & 88 & 27.7 & 94.1 & 14.9 \\
\hline
\end{tabular}

$\mathrm{PPV}=$ positive predictive value, $\mathrm{NPV}=$ negative predictive value 
anaphylactic reactions and emergency medication available, as there is a risk of evoking an adverse allergic reaction.

\section{Natural history}

The only data available on the natural history of nut allergies comes from follow-up studies in series of patients who are allergic to peanuts. Traditionally, it has been considered that peanut allergy is a persistent condition; in a study carried out in a cohort of thirty-two children from 1 to 14 years of age, followed for a period of 2-14 years, clinical reactivity to peanuts was found to be persistent (Bock \& Atkins, 1989). However, isolated cases of resolution of peanut allergy have been documented. Moreover, up to $10 \%$ of children of 2.5 years of age with positive skin tests to peanuts had negative results 3 years later. In the last few years, the possibility of outgrowing peanut allergy has gained acceptance. In several studies carried out on children with a positive history of peanut allergy, approximately $20 \%$ of cases outgrew their reactivity to peanuts. Factors predictive of resolution were: reduction in the size of skin tests or results becoming negative, a specific serum IgE to peanuts below $5 \mathrm{kU} / \mathrm{L}$, a 3 -year time interval since the last reaction, mild clinical reactions and isolated peanut allergy (Fleischer et al. 2003). In addition, the resolution of peanut allergy following bone marrow transplantation has been reported (Hourihane et al. 2005).

The recurrence of symptoms after tolerating peanuts has recently been described. Therefore, it seems advisable that after peanut allergy has been resolved, patients should maintain the therapeutic measures (epinephrine self-injection) so that they can promptly treat a possible adverse reaction. This recommendation should be maintained until significant quantities of peanuts have been ingested without any adverse effects over one or two years (Busse et al. 2002; Fleischer et al. 2004).

\section{Prevention}

The debate about the effect of different prevention strategies on the development of allergies to peanuts and other nuts is on-going. Besides general preventive hygienic and environmental measures in high-risk parents (i.e. those with a positive atopic history), mothers are recommended to avoid peanuts during pregnancy and lactation and advised to exclude foods containing peanuts from their infant's diet in the first 3 years of life. A systematic revision of preventive interventions carried out in high atopic-risk mothers show that the prescription of an avoidance diet of highly allergenic foods (e.g. egg, cow's milk, fish or peanuts) may significantly reduce the risk of developing atopic dermatitis in the first 2 years of life. On the other hand, the prescription of an avoidance diet during pregnancy does not seem to substantially reduce atopic risk in the future newborn (Kramer, 2001).

\section{Treatment}

The treatment of nut allergies should include information to patients and families about avoiding all forms of allergenic food and the severity of an adverse reaction in case of inadvertent ingestion. Patients and families should be instructed how to recognise the early symptoms of an allergic reaction and how to treat an anaphylactic reaction promptly (Sampson, 2002).

Once the nut allergy has been diagnosed, strict avoidance of the food should be recommended. A positive skin test result and/or the presence of specific serum $\operatorname{IgE}$ antibodies to the food without a positive oral challenge should not be the only reasons for prescribing an avoidance diet, except in cases of a convincing history of severe anaphylaxis after the ingestion of an isolated food. The avoidance of the implicated nut or of the whole group of nuts remains a controversial issue. In general, the full avoidance of all nuts and tree nuts is recommended, except if the patient is regularly consuming a particular nut species without any adverse effects. This recommendation, although perhaps excessively restrictive, is justified because of the possibility of cross-contamination between different nuts used as ingredients in processed foods, a possible ingredient substitution and the difficulty of identifying individual nut species in processed foods (Sicherer, 2002).

Patients and families must learn how to identify nuts on food labels and how to avoid high-risk situations, such as sharing foods or ingesting products which could contain nuts as ingredients. Unlike other adverse reactions, allergic responses to food can be elicited by minimal amounts or traces of the culprit food. Therefore, allergic individuals should carefully check the full composition of food before ingestion. The Codex Alimentarius Commission has established a list of common allergenic foods, which includes peanuts and other nuts. These foods should always be enumerated in the list of ingredients in the label, independently of the amount present in the food. Moreover, this Commission has proposed that the so-called ' $25 \%$ rule' (individual components in a food can be omitted in a label if their quantity in a processed food is below $25 \%$ in the final product) in labelling should be reduced to $5 \%$. However, in situations in which the foods are not prepared with known components (e.g. meals out, processed foods, etc.) the risk of an allergic reaction increases, because of the possibility of accidental ingestion in nonlabelled foods (minimal amounts present) or cross-contamination in processing or cooking in containers used previously for nuts. 'Hidden' nuts can be present in processed foods, such as ice creams, cakes, chocolates and other confectionery products. Indian and Chinese food frequently contain peanuts and other nuts. 'Buffet' restaurants can be a potential source of cross-contamination between different foods because the same cutlery is used for servings (Sicherer, 2002).

Food to which the patient is allergic can be accidentally ingested, even with the practice of strict avoidance measures. Therefore, patients and families should be instructed about the potential severity of allergic reactions to food and emergency therapeutic measures. The patient should always carry selfinjectable epinephrine and should be trained in its use. Traditionally, epinephrine administration has been recommended in the case of onset of severe symptoms. However, it is now accepted that epinephrine should be self-administered as soon as inadvertent exposure to an allergenic food is discovered. After epinephrine administration, the patient should be observed by medical personnel, typically in an emergency department where additional treatment may be administered if necessary. Antihistamines can be used by a patient suffering from an allergic reaction to a food as an additional treatment but never instead of epinephrine. 
Allergic reactions to food in school are a specific sort of problem. Food-allergic children should not be excluded from the school dining room, trips or other school activities. School personnel should be instructed in food allergy and the management of emergency situations. It is highly recommended that schools have a written emergency plan for a food-allergic child and pre-charged epinephrine for self-injection in first-aid emergency kits (Rhim \& McMorris, 2001).

Several studies have shown that parenteral immunotherapy with peanut extracts has an unacceptable risk/benefit ratio. Therefore, new therapeutic strategies are being investigated, such as treatment with humanised anti-IgE antibodies, which block the binding of $\mathrm{IgE}$ antibodies to their high-affinity (FceRI) and low-affinity (FceRII or CD23) receptors. This therapy also reduces FceRI expression on basophils and can inhibit specific $\mathrm{T}$ cell activation by interfering with the processing of antigen by antigen-presenting cells, which is mediated by FceRII and FceRI. In a randomised, double-blind placebocontrolled clinical trial carried out on eighty-four peanut-allergic patients, it was demonstrated that the monthly administration of a TNX-901(monoclonal IgG1 anti-IgE antibody) $450 \mathrm{mg}$ dose significantly increases tolerance to peanut ingestion in allergic patients from half a peanut $(178 \mathrm{mg})$ to almost nine peanuts $(2.805 \mathrm{mg})$. This effect can be clinically important in inadvertent ingestion (Leung et al. 2003). Other therapies are still in the pre-clinical investigation stage: for example, cytokines, immunotherapy with DNA-plasmids, recombinant allergenic proteins from peanut in which critical aminoacids for IgE binding have been substituted or peptides from peanut allergens which contain $\mathrm{T}$ cell epitopes (Eigenmann, 2003).

\section{Acknowledgements}

Supported by Fondo de Investigación Sanitaria, Ministerio de Sanidad y Consumo (grants RTIC G03/094 and C03/011)

\section{References}

Beyer K, Morrow E, Li XM, Bardina L, Bannon GA, Burks AW \& Sampson HA (2001) Effects of cooking methods on peanut allergenicity. J Allergy Clin Immunol 107, 1077-1081.

Bock SA \& Atkins FM (1989) The natural history of peanut allergy. J Allergy Clin Immunol. 83, 900-904.

Bock SA, Munoz-Furlong A \& Sampson HA (2001) Fatalities due to anaphylactic reactions to foods. J Allergy Clin Immunol 107, $191-193$.

Breiteneder H \& Ebner C (2000) Molecular and biochemical classification of plant-derived food allergens. J Allergy Clin Immunol 106, $27-36$.

Bruijnzeel-Koomen C, Ortolani C, Aas K, Bindslev-Jensen C, Bjorksten B, Moneret-Vautrin D \& Wuthrich B (1995) Adverse reactions to food. European Academy of Allergology and Clinical Immunology Subcommittee. Allergy 50, 623-635.

Burks W, Helm R, Stanley S \& Bannon GA (2001) Food allergens. Curr Opin Allergy Clin Immunol 1, 243-248.

Busse PJ, Nowak-Wegrzyn AH, Noone SA, Sampson HA \& Sicherer SH (2002) Recurrent peanut allergy. N Engl J Med 347, $1535-1536$.

Crespo JF, Pascual C, Burks AW, Helm RM \& Esteban MM (1995) Frequency of food allergy in a paediatric population from Spain. Pediatr Allergy Immunol 6, 39-43.
Eigenmann PA (2003) Future therapeutic options in food allergy. Allergy 58, 1217-1223.

Emmett SE, Angus FJ, Fry JS \& Lee PN (1999) Perceived prevalence of peanut allergy in Great Britain and its association with other atopic conditions and with peanut allergy in other household members. Allergy 55, 380-385.

Ewan PW (1996) Clinical study of peanut and nut allergy in 62 consecutive patients: new features and associations. BMJ 312, 1074-1078.

Fleischer DM, Conover-Walker MK, Christie L, Burks AW \& Wood RA (2003) The natural progression of peanut allergy: Resolution and possibility of recurrence. J Allergy Clin Immunol 112, 183-189.

Fleischer DM, Conover-Walker MK, Christie L, Burks AW \& Wood RA (2004) Peanut allergy: recurrence and its management. J Allergy Clin Immunol 114, 1195-1201.

Grundy J, Matthews S, Bateman B, Dean T \& Arshad SH (2002) Rising prevalence of allergy to peanut in children: Data from 2 sequential cohorts. J Allergy Clin Immunol 110, 784-789.

Hourihane JO, Dean TP \& Warner JO (1996) Peanut allergy in relation to heredity, maternal diet, and other atopic diseases: results of a questionnaire survey, skin prick testing, and food challenges. BMJ 313, 518-521.

Hourihane JO, Rhodes HL, Jones AM, Veys P \& Connett GJ (2005) Resolution of peanut allergy following bone marrow transplantation for primary immunodeficiency. Allergy 60, 536-537.

Howell WM, Turner SJ, Hourihane JO, Dean TP \& Warner JO (1998) HLA class II DRB1, DQB1 and DPB1 genotypic associations with peanut allergy: evidence from a family-based and case-control study. Clin Exp Allergy 28, 156-162.

Kay AB (2001) Allergy and allergic diseases. First of two parts. $N$ Engl J Med 344, 30-37.

Kramer MS (2001) Maternal antigen avoidance during lactation for preventing atopic disease in infants of women at high risk (Cochrane Review). In The Cochrane Library 1. Oxford: Update Software.

Kull I, Hallner E, Lilja G, Ohman-Johansson AC, Oman H \& Wickman M (1999) Peanut oil in vitamin A and D preparations: reactions to skin test and manifestation of symptoms. Pediatr Allergy Immunol 10, 21-26.

Legendre C, Caillat-Zucman S, Samuel D, Morelon S, Bismuth H, Bach JF \& Kreis H (1997) Transfer of symptomatic peanut allergy to the recipient of a combined liver-and-kidney transplant. $N$ Engl $J$ Med 337, 822-824.

Leung DY, Sampson HA, Yunginger JW, Burks AW Jr, Schneider LC, Wortel CH, Davis FM, Hyun JD \& Shanahan WR Jr (2003) Avon Longitudinal Study of Parents and Children Study Team. Effect of anti-IgE therapy in patients with peanut allergy. N Engl J Med 348, 986-993.

Midoro-Horiuti T, Brooks EG \& Goldblum RM (2001) Pathogenesisrelated proteins of plants as allergens. Ann Allergy Asthma Immunol 87, 261-271.

Moneret-Vautrin DA, Rance F, Kanny G, Olsewski A, Gueant JL, Dutau G \& Guerin L (1998) Food allergy to peanuts in France evaluation of 142 observations. Clin Exp Allergy 28, 1113-1119.

Nowak-Wegrzyn AH, Sicherer SH, Conover-Walker MK \& Wood RA (2001) Food allergy after pediatric organ transplantation with tacrolimus immunosuppression. J Allergy Clin Immunol 108, 146-147.

Ortolani C, Ballmer-Weber BK, Hansen KS, et al. (2000) Hazelnut allergy: a double-blind, placebo-controlled food challenge multicenter study. J Allergy Clin Immunol 105, 577-581.

Pastorello EA, Vieths S, Pravettoni V, et al. (2002) Identification of hazelnut major allergens in sensitive patients with positive double-blind, placebo-controlled food challenge results. J Allergy Clin Immunol 109, 563-570.

Phan TG, Strasser SI, Koorey D, McCaughan GW, Rimmer J, Dunckley H, Goddard L \& Adelstein S (2003) Passive transfer of nut allergy after liver transplantation. Arch Intern Med 163, 237-239. 
Primeau MN, Kagan R, Joseph L, Lim H, Dufresne C, Duffy C, Prhcal D \& Clarke A (2000) The psychological burden of peanut allergy as perceived by adults with peanut allergy and the parents of peanut-allergic children. Clin Exp Allergy 30, $1135-1143$.

Rance F, Bidat E, Bourrier T \& Sabouraud D (2003) Cashew allergy: observations of 42 children without associated peanut allergy. Allergy 58, 1311-1314.

Rhim GS \& McMorris MS (2001) School readiness for children with food allergies. Ann Allergy Asthma Immunol 86, $172-176$.

Roux KH, Teuber SS \& Sathe SK (2003) Tree nut allergens. Int Arch Allergy Immunol 131, 234-244.

Sampson HA (2001) Utility of food-specific IgE concentrations in predicting symptomatic food allergy. J Allergy Clin Immunol 107, 891-896.

Sampson HA (2002) Peanut allergy. N Engl J Med 346, 1294-1299.

Sicherer SH, Burks AW \& Sampson HA (1998) Clinical features of acute allergic reactions to peanut and tree nuts in children. Pediatrics 102, 1-6.
Sicherer SH, Munoz-Furlong A, Burks AW \& Sampson HA (1999) Prevalence of peanut and tree nut allergy in the US determined by a random digit dial telephone survey. J Allergy Clin Immunol 103, 559-562.

Sicherer SH, Furlong TJ, Maes HH, Desnick RJ, Sampson HA \& Gelb BD (2000) Genetics of peanut allergy: a twin study. J Allergy Clin Immunol 106, 53-56.

Sicherer SH, Furlong TJ, Munoz-Furlong A, Burks AW \& Sampson HA (2001) A voluntary registry for peanut and tree nut allergy: characteristics of the first 5149 registrants. J Allergy Clin Immunol 108, 128-132.

Sicherer SH (2002) Clinical update on peanut allergy. Ann Allergy Asthma Immunol 88, 350-361.

Tariq SM, Stevens M, Matthews S, Ridout S, Twiselton R \& Hide DW (1996) Cohort study of peanut and tree nut sensitisation by age of 4 years. BMJ 313, 514-517.

Teuber SS, Comstock SS, Sathe SK \& Roux KH (2003) Tree nut allergy. Curr Allergy Asthma Rep 3, 54-61.

Zeiger RS (2003) Food allergen avoidance in the prevention of food allergy in infants and children. Pediatrics 111, 1662-1671. 